\title{
Optimisation of Low Temperature Difference Solar Stirling Engines using Genetic Algorithm
}

\author{
Kwanchai Kraitong, Khamid Mahkamov ${ }^{*}$ \\ School of Computing, Engineering and Information Sciences, Northumbria University, \\ Newcastle upon Tyne, NE1 8ST, UK* \\ *Corresponding author. Tel:+44 191 2274739, Fax: +44 1912437630 , \\ Email: khamid.mahkamov@northumbria.ac.uk
}

\begin{abstract}
This paper presents results of theoretical investigations on the determination of optimal design parameters of a Low Temperature Difference (LTD) Solar Stirling Engine using optimisation method based on Genetic algorithms. The developed thermodynamic mathematical model of the engine takes into account hydraulic and mechanical losses in the engine's working process and this model was coupled to the optimisation algorithm. A set of such design parameters as the stroke of the displacer and diameter and stroke of the power piston and the thickness of the regenerator placed in the displacer have been considered as variables. The engine's performance parameter such as the brake power is used as the objective function of the optimisation algorithm. The GA code is implemented in MATLAB. The accuracy of the optimal design engine's performance is examined using 3D CFD modelling of the working process of the engine. The set of design parameters obtained from the optimisation procedure provides the noticeable improvement of the engine's performance compared with the performance of the original LTD Solar Stilring engine with the same operating condition.
\end{abstract}

Keywords: LTD Stirling engine, Second-order mathematical model, Mechanical losses, CFD, Genetic algorithm.

\section{Nomenclature}

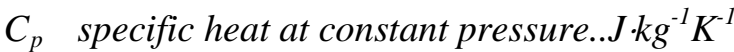

$C_{v} \quad$ specific heat at constant volume ...J $\mathrm{kg}^{-1} \mathrm{~K}^{-1}$

$D_{p}$ diameter of piston..................................m

$D_{D}$ diameter of displacer............................m

$f \quad$ frequency...............................................Hz

$H_{d}$ thickness of regenerator.........................m

$m$ mass of the gas in the control volume..... kg

maxvalue maximum fitness value in the value map

$\dot{m}_{i} \quad$ inlet mass flow rate............................ $\mathrm{kg} \cdot \mathrm{s}^{-1}$

$\dot{m}_{o} \quad$ outlet mass flow rate.......................... $\mathrm{kg} \cdot \mathrm{s}^{-1}$

$P_{b} \quad$ brake power.........................................W

$P_{c}$ pressure in the compression space........Pa

$P_{c 1}$ pressure in the compression space in the displacer chamber. $P a$

$P_{c 2}$ pressure in compression space in the piston cylinder...............................................Pa

$P_{e} \quad$ pressure in the expansion space.............Pa

$P_{i} \quad$ indicated power....................................W

$Q \quad$ heat transfer rate...................................W

$T$ total crank torque................................ N.m

$T_{b} \quad$ frictional torque of the rolling bearing. $N \cdot m$

$T_{i} \quad$ inlet temperature........................................

$T_{o} \quad$ outlet temperature.....................................

$T_{p} \quad$ piston crank torque............................ $N \cdot m$

$t \quad$ time................................................... sec
$V_{c} \quad$ volume of the compression space.............. $m^{3}$

$V_{c 1}$ volume of the compression space in the displacer chamber................................. $m^{3}$

$V_{c 2}$ volume of the compression space in the piston cylinder..................................... $\mathrm{m}^{3}$

$V_{d c}$ dead volume of the compression space... $m^{3}$

$V_{d e}$ dead volume of the expansion space......... $m^{3}$

$V_{e}$ volume of the expansion space................... ${ }^{3}$

$V_{S P}$ swept volume of the piston ... $m^{3}$

$V_{S D}$ swept volume of the displacer................... $m^{3}$

$W$ work........................................................ J

$W_{b} \quad$ cyclic brake work......................................

$W_{c}$ work of the compression space.................J

$W_{e}$ work of the expansion space.....................J

$x \quad$ current displacement of the piston............

$x_{0} \quad$ stroke of the piston......................................

$y$ current displacement of the displace.......m

$y_{0} \quad$ stroke of the displacer ..............................m

$Z_{D} \quad$ stroke of displacer...................................m

$Z_{p} \quad$ stroke of piston......................................m

$\theta \quad$ piston crank angle...................................rad

$\varphi$ displacement phase angle of the piston.. rad

$k, \varepsilon$ turbulent kinetic energy and dissipation turbulent kinetic energy. $m^{2} \cdot s^{-2}$

Value. fitness value 


\section{Indroduction}

Low Temperature Difference (LTD) Stirling engines, though provide low electricity production, can be used as solar energy and waste heat recovery system due to their simple design and low cost production [1]. There is an interest towards development of LTD Stirling engines for deployment in rural areas of developing countries for production of power on the small scale. Because of this reason, numerous studies have been conducted for determination of optimal design parameters of LTD Stirling engines. Several thermodynamic mathematical models have been used for the determination of the optimum power and efficiency of such engines [2-7]. Furthermore, a considerable work was done on the development of optimisation algorithms for conventional high temperature engines $[8,9]$. The search method which uses the Genetic algorithm (GA) code coupled to the mathematical model accounting for heat and mechanical losses using the theorem of forced work was presented by Altman in [9]. This work presents the determination of optimal design parameters of a LTD Stirling engine using GA optimization method, coupled to the second-order model of the engine, which takes into account hydraulic and mechanical losses, developed by Kraitong and Mahkamov [10]. Additionally, 3D CFD simulations using CFD FLUENT software were performed to calibrate results of the optimization calculations.

\section{Physical model}

Figure 1a represents a schematic diagram of the kinematical gamma LTD Stirling engine. The main components of the LTD Stirling engine are the power piston and displacer with corresponding cylinders, the hot and cold plates, , the regenerator placed inside the displacer and the drive mechanism with the flywheel. In this paper, a twin-power piston LTD Stirling engine, see Fig. 1b, manufactured by Kongtragool and Wongwises [11] is used in numerical investigations. This engine consists of two power pistons and one displacer with the built-in regenerator. The regenerator is made of coarse stainless steel mesh placed in the casing perforated at its top and bottom. Table 1 presents data on the physical dimensions of this Stirling engine.

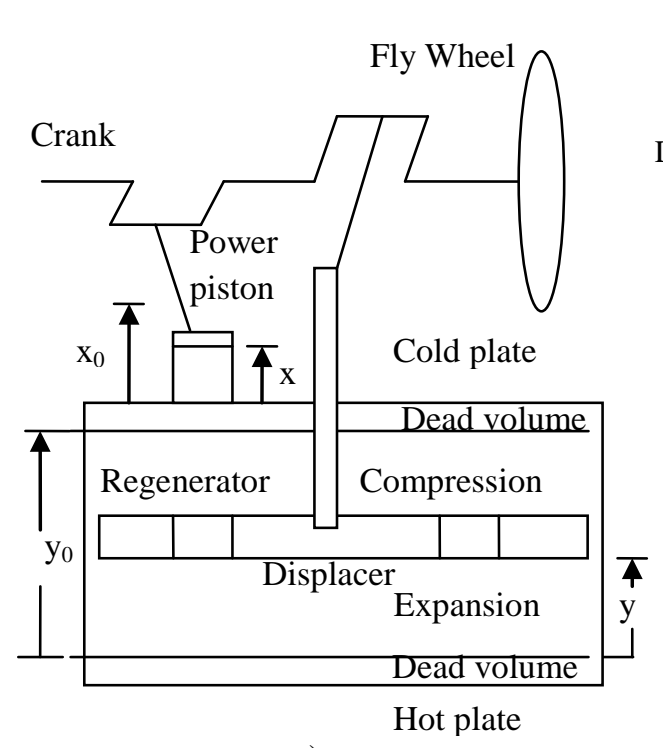

a)

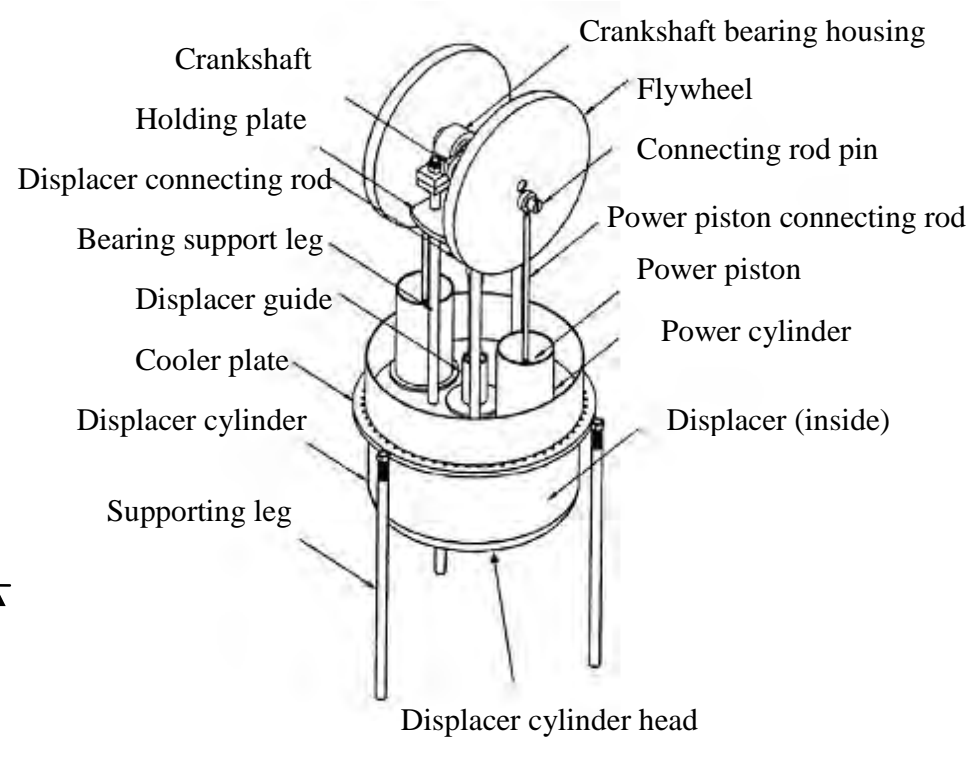

b)

Fig. 1. a) A Schematic diagram of the kinematic gamma LTD Stirling engine and b) The physical characteristic of the twin power piston LTD Stirling from Kongtragool and Wongwises [11]. 
Table 1. Dimensions of the LTD Stirling engine manufactured by Kongtragool and Wongwises [11]

\begin{tabular}{lc}
\hline \multicolumn{1}{c}{ The geometric data of a twin power piston LTD Stirling engine } & Value \\
\hline working piston stroke $(\mathrm{m})$ & 0.0826 \\
working piston diameter(m) & 0.083 \\
working piston swept volume $\left(\mathrm{m}^{3}\right)$ & $893.8 \times 10^{-6}$ \\
displacer piston stroke $(\mathrm{m})$ & 0.0795 \\
displacer piston diameter $(\mathrm{m})$ & 0.32 \\
displacer piston swept volume $\left(\mathrm{m}^{3}\right)$ & $6393.8 \times 10^{-6}$ \\
swept volume ratio & 7.15 \\
displacement phase angle of the pistons $\left(^{\circ}\right)$ & 90 \\
\hline
\end{tabular}

\section{Modelling Procedure}

\subsection{Thermodynamic modelling}

The second-order mathematical model taking into account the pressure drop and the mechanical losses developed by Kraitong and Mahkamov [10] was used for the performance prediction of the engine. This model is the modification of that developed by Timoumi et al. [7] and Urieli [12]. The equations of energy and mass conservation for each control volume are expressed as follows:

$C_{v} \frac{d(m T)}{d t}=d Q-\frac{d W}{d t}-\dot{m}_{o} C_{p} T_{o}+\dot{m}_{i} C_{p} T_{i}$

$\frac{d m}{d t}=\dot{m}_{o}-\dot{m}_{i}$

Work done by the working gas inside the compression space and the expansion space can be calculated as $\frac{d W_{c}}{d t}=P_{c} \frac{d V_{c}}{d t}$ and $\frac{d W_{e}}{d t}=P_{e} \frac{d V_{e}}{d t}$, respectively.

Volumes of the compression and expansion spaces are expressed as

$$
\begin{aligned}
& V_{c}=V_{d c}+\frac{V_{S P}}{2}(1+\cos (\theta-\varphi))+\frac{V_{S D}}{2}(1-\cos \theta) \\
& V_{e}=V_{d e}+\frac{V_{S D}}{2}(1+\cos \theta)
\end{aligned}
$$

where $V_{S P}=\pi \frac{D_{p}^{2}}{4} Z_{p}$ and $V_{S D}=\pi \frac{D_{D}^{2}}{4} Z_{D}$.

In order to determine the brake cyclic power, the kinetic motion equations of the mechanical transmission system of the reciprocating engine proposed by Guzzomi et al. $[13,14]$ were used. The determination of the frictional forces in the sealing rings of the displacer rod is carried out using methodology described in [15]. These results were used to calculate the torque induced by the pistons $\left(T_{p}\right)$. The brake cyclic work and the brake cyclic power, therefore, are calculated as 


$$
\begin{aligned}
& T=\sum T_{p} \\
& W_{b}=\oint\left(\frac{d W_{b}}{d t}\right) d t=\int_{0}^{\tau}\left(\left(T-T_{b}\right) \frac{d \theta}{d t}\right) d t \\
& P_{b}=W_{b} f
\end{aligned}
$$

For numerical calculations, the cycle was split into 1000 time-steps and calculations were performed until the pressure and temperature curves converged and the overall heat balance in the system was reached.

\subsection{CFD modelling}

To achieve better understanding of the working process of the LTD Stirling engine and obtain more accuracy in the performance prediction, 3D CFD modeling using the standard $k-\varepsilon$ turbulence model for a compressible flow was carried out to investigate the work of the engine. Commercial CFD software, FLUENT was used to perform CFD simulations of the working process of the engine. During the simulations the movement of pistons was taken into account and the regenerator of the engine was treated as a homogeneous porous medium. The subroutines describing displacements of the pistons and the displacer were written and then connected to the main body of the programme. The cycle was divided into equal 500 time-steps and calculations were performed using a high performance computer. The average gas temperature and pressure in each engine's working space were monitored during calculations in order to determine whether the steady-state condition was reached in the simulated operation of the engine.

\subsection{Optimisation modelling}

Genetics algorithm is a stochastic optimisation method based on the mechanism of natural selection for survival as the procedure in order to obtain optimal results [16]. The real-valued GA or the continuous GA is applied in this work for the quantitative limitation and the reduction of the computing time [17]. The structure of the continuous GA of the LTD Stirling engine is represented in Fig. 2.

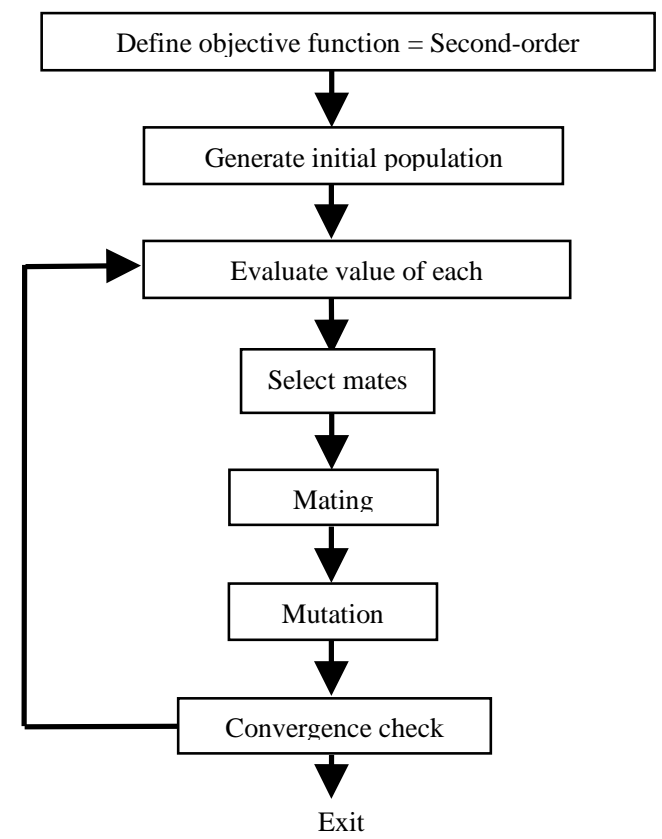

Fig. 2. The structure of the continuous GA of the LTD Stirling engine. 
Several original engine design and operational parameters, namely the diameter of the displacer of $0.32 \mathrm{~m}$, the engine speed of $46.5 \mathrm{rpm}$, the solar irradiation of $5097 \mathrm{~W} / \mathrm{m}^{2}$ created using a solar simulator and the cooler surface temperature of $307 \mathrm{~K}$, are accepted to be fixed as constant values in this work. There are only four engine design parameters are defined as variables. These are the diameter and the stroke of the power piston, the stroke the displacer and the thickness of the regenerator:

Chromosome $=\left(D_{p} ; Z_{p} ; Z_{D} ; H_{d}\right)$

The upper and the lower bound of each variable are as follows;

$0.02<D_{p}<0.13 \quad ; D_{p}$ is diameter of piston (m)

$0.04<Z_{p}<0.3 \quad ; Z_{p}$ is stroke of piston (m)

$0.04<Z_{D}<0.3 \quad ; Z_{D}$ is stroke of displacer (m)

$0.01<H_{d}<0.2 \quad ; H_{d}$ is thickness of regenerator $(\mathrm{m})$

The above boundaries are defined based on the practical manufacturing and design considerations. The maximum diameter of the piston is limited by the diameter of the cold plate which is equal to the fixed displacer diameter. The range of the displacer stroke to be investigated is typical for displacers of LTD Stirling engines [18]. Only one of the engine's performances, namely the brake power, is defined to be the chromosome value because the heat source is solar energy which is assumed to be cost-free. The the brake power of the engine obtained using the developed second-order mathematical model is used as the objective function:

Brakepower $=f($ chromosome $)=f\left(D_{p} ; Z_{p} ; Z_{D} ; H_{d}\right)$

In GA, there is no effect of the guessed initial chromosomes on the convergence of the solution, thus the initial population is created by using the absolutely random procedure. A generated initial population is in the matrix formation of various chromosomes. The size of the population effects the convergence in the optimization procedure. The number of chromosomes between 30 and 100 is the typical size to operate GA [19]. In this study, the number of chromosomes in a generation of 30 is used. The chromosome value which is the brake power is evaluated by the fitness function for locating in the value map of each generation [20]:

Fitnessvalue $=\frac{1}{1+\text { maxvalue }- \text { value }}$

The fitness value of each chromosome is descending order to determine survival chromosomes for the next generation. The number of survival chromosomes is defined by the selection rate of 0.5 from the weighted random pairing selection and the rank weighting technique [17]. The single point crossover is used for the mating process that the parents are operated by the reproduction operator to produce some offsprings for the next generation. Fittest chromosomes of the ranking are randomly selected to be the parents for the reproduction operation. The second operator of the reproduction called the mutation is used as a tool to avoid finding only the local solution. The mutation rate of 0.2 , though probably is high, results in the gradual convergence and ensures that the global maximum is not missed out in during simulations [17]. 
Finally, the new generation is produced and the population of new design parameters in this generation is then evaluated by the developed thermodynamic model and the fitness function is checked for the ranking until the solution found satisfying the termination condition. The maximum number of generation in the computing process of 80 is defined to obtain the convergence of this algorithm. The optimisation code was modified from [19] and implemented in MATLAB. In this case, the continuous GA was used to obtain the optimal design parameters for the performance's improvement of an original LTD Stirling engine. Simulations were, thus, conducted for the same operating condition. A set of optimal design parameters from the numerical simulations was then used to create the engine mesh for the 3D CFD simulation to more accurately predict the engine power.

\section{Results from optimisation cacluations}

The modelling of the engine with the SM15-matrix regenerator was performed for the constant solar flux of $5097 \mathrm{~W} / \mathrm{m}^{2}$, the cooler surface temperature of $307 \mathrm{~K}$, the engine speed of $46.5 \mathrm{rpm}$ with air at 1 bar pressure used as a working fluid. Figure 3 represents the best brake power for each generation. The best brake power first sharply increases and then gradually reaches the convergence with its value of $1.515 \mathrm{~W}$. The design parameters of this generation are presented in Table 2. The corresponding indicated power is $1.668 \mathrm{~W}$.

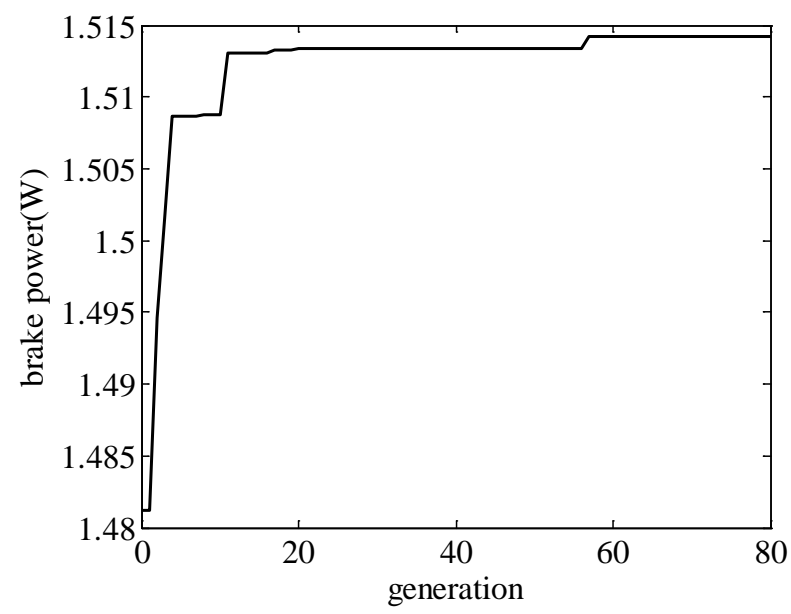

Fig. 3. The best brake power of each generation as the function of generations.

Table 2. The first set of optimal engine design parameters obtained from optimisation simulation.

\begin{tabular}{lc}
\hline \multicolumn{1}{c}{ Optimal engine design parameters } & Value \\
\hline working piston stroke $(\mathrm{m})$ & 0.228 \\
working piston diameter(m) & 0.065 \\
displacer piston stroke (m) & 0.074 \\
displacer thickness (m) & 0.056 \\
\hline
\end{tabular}

However, it could be seen that the stroke of the power piston of $0.228 \mathrm{~m}$ which is much longer than the stroke of the displacer of $0.074 \mathrm{~m}$. This may be unsuitable for the practical engine. Thus, the power piston and displacer strokes were fixed at $0.1 \mathrm{~m}$ and a new set the optimisation simulations with two variables were run. Optimal engine parameters from the second run are presented in Table 3 and the maximum brake and indicated power is $1.346 \mathrm{~W}$ and $1.47 \mathrm{~W}$, respectively. There is only $11 \%$ reduction in power when compared with the results of the first optimization run. 
Table 3. The second set of optimal engine design parameters is obtained from optimisation simulation.

\begin{tabular}{ll}
\hline \multicolumn{1}{c}{ Optimal engine design parameters } & Value \\
\hline working piston stroke (m) & 0.1 \\
working piston diameter(m) & 0.1 \\
displacer piston stroke (m) & 0.095 \\
displacer thickness (m) & 0.058 \\
\hline
\end{tabular}

Finally, two engines with optimal engine parameters shown in Tables 2 and 3 were modelled using 3D CFD simulation. The indicated power of the first and the second engine calculated from P-V diagrams which are shown in Fig. 4a and Fig. 4b are $1.427 \mathrm{~W}$ and $1.352 \mathrm{~W}$, respectively. 3D CFD modelling results demonstrate that the second-order thermodynamic model used in oprimisation procedure has an adequate accuracy in the prediction of the engine performance.

\section{Conclusion}

The developed second-order mathematical model of the LTD Stirling engine was developed which accounts for hydraulic and heat losses in the working process and mechanical losses in the engine. This model was used with GA optimisation code. As a result of optimization simulations a set of design parameters for the engine was obtained which provides a considerable improvement in the performance. Results obtained using the developed secondorder thermodynamic model were calibrated using 3D CFD modeling technique. The optimisation procedure developed in his work can be applied to improve the design of a wide range of Stirling engines, including high temperature ones.

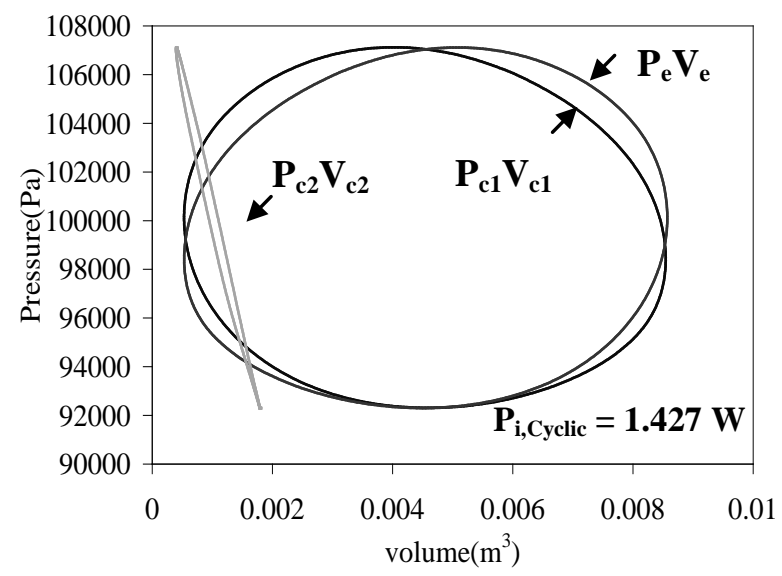

a)

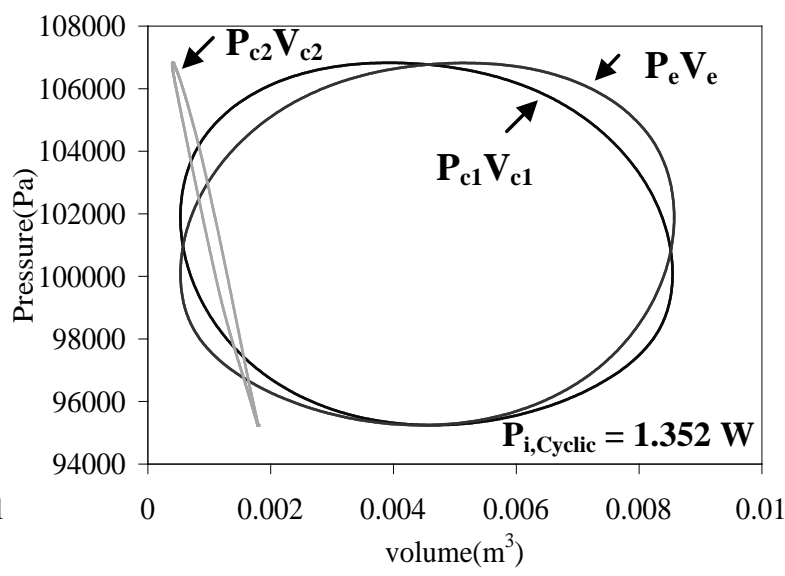

b)

Fig. 4. 3D CFD modeling results: a) $P$-V diagrams for the first optimal parameters set obtained using and b) P-V diagrams for the second optimal parameters set

\section{Acknowledgements}

This work is a part of a PhD study which is supported by the Ministry of Science and Technology of the Royal Thai Government. Authors also would like to thank Professor Somchai Wongwises and Assistant Professor Bancha Kongtragool for providing data on their twin power piston LTD Stirling engine. 


\section{References}

[1] B. Kongtragool, S. Wongwises, A review of solar-powered Stirling engines and low temperature differential Stirling engines, Renewable and Sustainable Energy Reviews, 2003, pp. 131-154.

[2] L. Erbay, H. Yavuz, Analysis of the Stirling heat engine at maximum power conditions, Energy 22, 1996, pp. 645-650.

[3] S. Hsu, F. Lin, J. Chiou, Heat-transfer aspects of Stirling power generation using incinerator waste energy, Renewable Energy 28, 2003, pp. 59-69.

[4] A. Tavakolpour, A. Zomorodian, A. Golneshan, Simulation, construction and testing of a two-cylinder solar Stirling engine powered by a flat-plate solar collector without regenerator, Renewable Energy 33, 2008, pp. 77-87.

[5] N. Martaj, L. Grosu, P. Rochelle, Exergetical analysis and design optimisation of the Stirling engine, Int. J. of Exergy 3, 2006, pp. 45-46.

[6] B. Orunov, V. T. Krykov, A. P. Korobkov, K. Mahkamov, D. Djumanov, The first stage of the development of a small Stirling tri-generation power unit, Proceeding of 12th international Stirling engine conference, 2005, pp. 416-423.

[7] Y. Timoumi, I. Tlili, S. Nasrallah, Design and performance optimization of GPU 3 Stirling engines, Energy URL doi:10.1016/j.energy.2008.02.005.

[8] Y. C. Hsieh, T. C. Hsu, J. S. Chiou, Integration of a free-piston Stirling engine and a moving grate incinerator, Renewable Energy 33, 2008, pp. 48-54.

[9] A. Altman, SNAPpro: Stirling numerical analysis program, URL http://home.comcast.net/snapburner/SNAPpro ISEC 2004.pdf, 2004.

[10]K. Kraitong, K. Mahkamov, Thermodynamic and CFD Modelling of Low Temperature Difference Stirling engines, Proceeding of 14th international Stirling engine conference, 2009.

[11] B. Kongtragool, S.Wongwises, Performance of a twin power piston low temperature differential Stirling engine powered by a solar simulator, Solar Energy 81, 2007, pp. 884-895.

[12]I. Urieli, Stirling Cycle Machine Analysis, URL http://www.ent.ohiou.edu/ urieli/stirling/me422.html>, 2008.

[13]D. C. Hesterman, B. J. Stone, A systems approach to the torsional vibration of multicylinder reciprocating engines and pumps, Proc. IMechE 208, 1994, pp. 395-408.

[14]A. L. Guzzomi, D. C. Hesterman, B. J. Stone, The effect of piston friction on engine block dynamics, Proc. IMechE 221, 2007, pp. 227-289.

[15]K. Mahkamov, D. Ingham, Analysis of the Working Process and Mechanical Losses in a Stirling Engine for a Solar Power Unit, J. of Solar Energy Engineering 121, 1999, pp. 121-127.

[16]D. E. Goldberg, Genetic Algorithms in Search, Optimization \& Machine Learning, Addison-Wesley Publishing Company, USA, 1989, ISBN 0- 201-15767-5.

[17] R. L. Haupt, S. E. Haupt, Practical Genetic Algorithm, John Wiley \& Sons, USA, Edition 2nd, 2004, ISBN 0-471-45565-2.

[18]J. R. Senft, An Introduction to Low Temperature Differential Stirling Engines, Moriya Press, USA, 2007, ISBN-13: 978-0965245517.

[19]A. M. S. Zalzala, P. J. Fleming, Genetic Algorithms in Engineering Systems, The Institution of Electrical Engineers, UK, 1997, ISBN 0-85296- 902-3.

[20]S. Elisaveta, B. Natasha, BASIC-A genetic algorithm for engineering problems solution, Computers and Chemical Engineering 30, 2006, pp. 1293-1309. 